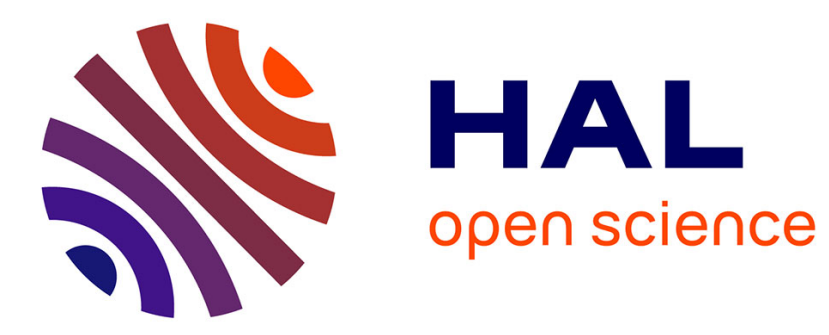

\title{
THEORETICAL STUDY OF THE SPATIAL RESOLUTION OF X-RAY MICROANALYSIS IN ANALYTICAL ELECTRON MICROSCOPY
}

\author{
K. Murata, M. Kawamura, K. Nagami
}

\section{- To cite this version:}

K. Murata, M. Kawamura, K. Nagami. THEORETICAL STUDY OF THE SPATIAL RESOLUTION OF X-RAY MICROANALYSIS IN ANALYTICAL ELECTRON MICROSCOPY. Journal de Physique Colloques, 1984, 45 (C2), pp.C2-393-C2-396. 10.1051/jphyscol:1984289 . jpa-00224004

\author{
HAL Id: jpa-00224004 \\ https://hal.science/jpa-00224004
}

Submitted on 1 Jan 1984

HAL is a multi-disciplinary open access archive for the deposit and dissemination of scientific research documents, whether they are published or not. The documents may come from teaching and research institutions in France or abroad, or from public or private research centers.
L'archive ouverte pluridisciplinaire HAL, est destinée au dépôt et à la diffusion de documents scientifiques de niveau recherche, publiés ou non, émanant des établissements d'enseignement et de recherche français ou étrangers, des laboratoires publics ou privés. 


\author{
K. Murata, M. Kawamura and K. Nagami \\ University of Osaka Prefecture, Sakai, Osaka 591, Japan
}

Résumé-La résolution spatiale de la microanalyse par rayons $\mathrm{X}$ a été étudiée par des calculs Monte-Carlo, en incluant la production d'électrons secondaires. Les résultats pour $\mathrm{Au} \mathbf{M} \alpha$ dans un film mince d'or de $1000 \AA$ à $100 \mathrm{keV}$ diffĕrent de ceux obtenus sans tenir compte de la production d'électrons secondaires. Des calculs ont été faits avec la section efficace de Mott au lieu de celle de Rutherford écrantée, pour la diffusion élastique. Des différences notables sont trouvées entre les trois modèles.

Abstract - The spatial resolution of $\mathrm{X}$-ray microanalysis has been investigated by Monte Carlo calculations, including knock-on secondary electron production. The results for $\mathrm{AuM} \alpha$ in a $1000 \AA$ thin $\mathrm{Au}$ film at $100 \mathrm{keV}$ showed an appreciable difference from the ones without knock-out events. Also calculations have been done with the Mott cross-section instead of the screened Rutherford cross-section for elastic scattering. A significant difference was found in the results among the three models.

\title{
I Introduction
}

Recently, thin film X-ray analyses have been performed with a very fine probe of a few nanometers. One of the interests of many microscopists has been to what extent electron scattering in a sample influences the ultimate resolution of X-ray analysis. This problem has been investigated theoretically by many authors with various models, such as analytical [1-3] and Monte Carlo calculations [4-8]. There is a general agreement among the predicted resolutions by these methods. However, there is room to improve the simulation model for Monte Carlo calcalation which is said to be more flexible and accurate at present. A recent paper [9] pointed out that knock-on secondary electrons may have a large effect on the resolution. The present paper reports a study of the ultimate resolution in a gold film with a Monte Carlo calculation incorporating knock-on secondary electron production model. Moreover, some examination will be done with the mott cross-section instead of the screened Rutherford cross-section for elastic scattering.

\section{Calculation Model}

The present knock-on secondary electron production model is depicted schematically in Fig. 1. An incident electron penetrates a small step length along the initial direction, which is distributed exponentially around the mean free path of the electron. The electron collides with an atom at Point $\mathbf{P}_{1}$, either elastically or inelastically, depending on the scattering probability (in the figure an elastic event occured). When inelastic scattering occurs, pursuit of a primary electron is interrupted and knock-on electron tracked until it slows down to some energy below the critical excitation energy. Finishing the trajectory tracking of the secondary electron, the primary electron trajectory is resumed. In this model secondary electrons with a large energy transfer greater than some critical energy $\mathrm{E}_{c}$ are picked up from various inelastic scattering events as a discrete process. The continuous 
energy loss which results from collected small energy transfers is given by the following equation, substracting the energy loss due to discrete inelastic scattering events from the regular Bethe equation:

$$
\left[\frac{d E}{d s}\right]_{\varepsilon c}=\left[\frac{d E}{d s}\right]_{\text {Bethe }}\left[\frac{d E}{d s}\right]_{\text {single }}
$$

where

$$
\begin{gathered}
{\left[\frac{d E}{d s}\right]_{\text {single }}=\sum N i Z i \int_{\varepsilon_{\mathbf{c}}}^{1 / 2} E \varepsilon\left[\frac{d \sigma}{d \varepsilon}\right] d \varepsilon} \\
N i=\rho N_{A} c_{i} / A i
\end{gathered}
$$

$\varepsilon, \varepsilon_{\mathrm{c}}$ represent an energy transfer and a critical energy transfer normalized by the initial energy, respectively. A value of 0.001 was used for $\varepsilon_{c}$. We adopted the Moller crosssection for electron-electron collision, $\mathrm{d} \sigma / \mathrm{d} \varepsilon$. For calculation of angular deflection due to elastic scattering the screened Rutherford equation was used in the same way as in a previous paper [5]. Also calculations were tried with the Mott cross-section and knock-on secondary electron production (here we call it the MK model). The Mott cross-section at an arbitrary energy was obtained by an interpolation of the data at representative energies [11]. This cross-section is more important for a heavy element. For the ionization cross-section the following Bethe type expression was used.

$$
Q(U)=\text { constant. } \ln (U) / U
$$

To calculate the spatial distribution of the generated X-ray intensity, we divided a film into ten layers. Each layer was divided into concentric donut-shaped volumes with subdivisions of $20 \AA$. The calculations were done for a $1000 \AA$ thin gold film at $100 \mathrm{kV}$. The number of incident electrons is 20,000 .

\section{Results and Discussions}

1. Energy distribution of transmitted electrons.

In Fig. 2 a typical example of the energy distribution of transmitted electrons is shown to demonstrate a significant difference between the knock-on electron production model and the old model. With the old model most of the electrons are transmitted with nearly the incident energy. There is only a small fraction of transmitted electrons with an energy loss of several keV which are caused by a long travelling path due to large elastic scattering angles. While the new model gives a broader distribution near the incident energy and finite distribution over the whole region of energy even though the number of electrons involved is small. It was found that most electrons with energy between 50 and $100 \mathrm{keV}$ are primary electrons and electrons between 0 and $50 \mathrm{keV}$ are knock-on secondary electrons. Although the number of these electrons is small, they may contribute to a broader electron spreading.

\section{Spatial spreading of generated $X$-ray intensity.}

In Fig. 3 the $\mathrm{X}$-ray intensity distribtutions at the top and the bottom layers are shown as a function of radial distance. At the top layer a clear difference is seen between the results with and without the knock-on production. Secondary electrons show a wider diffusion at the surface. At the bottom layer there is still an appreciable difference although its effects are screened by a large angular deflection. The figure also shows a comparision with the MK model. At the top layer this model predicts a wider distribution than the other two. But at the bottom a sharper distribution is obtained to a distance of about $400 \AA$ with the Mott cross-section. Therefore, the new cross-section predicts that $\mathrm{X}$-ray generation is concentrated more around the incident direction. However, as 
anticipated from the result at the top layer, the MK model gives a larger intensity at the tail of the distribution. Fig. 4 shows the result in Fig. 3 in a normal scale. Note that the distributions are not Gaussian as pointed out by Jones [2].

\section{Spatial Resolution of X-ray Analysis}

To see the spatial spreading of generated X-ray intensities in the whole region of the film, we plotted the iso-contours of $\mathrm{Au} \mathrm{M} \alpha \mathrm{X}$-ray intensities in Fig. 5. The results with the three models are compared for iso-contours inside which integrated $\mathbf{X}$-ray intensities are 60,80 and $90 \%$ of the total intensity. As predicted by many authors, the distributions have a conical shape. We can see a clear difference between the resultss with (----) and without (....) knock-on secondary production. The difference becomes large with an increase in integrated intensity. Since in the present model atomic electrons are assumed to be free electrons, the accuracy of the cross-sections is not good for tightly bounded electrons such as $\mathrm{K}$ and $\mathrm{L}$-shell electrons. Therefore, the knock-on model may overestimate the electron spreading. Although the error is not evaluated at present, it can be improved by introducing [13] the ionization potential into the cross-section in the future. Fig. 6 shows the integrated $\mathrm{X}$-ray intensity as a function of radial distance corresponding to Fig. 5. The resolution obtained from this figure according to the definition of the spatial resolution by the cylindrical diameter within which $90 \%$ of the total intensity is contained. They are 464,560 and $880 \AA$ without, with knock-on model and with the MK model, respectively. A gradual saturation of the intensity gives a poor resolution with the Mott cross-section inspite of faster rise-up near the center. It may not be appropriate to apply automatically this resolution to actual analysis of the sample with various types of boundary. We obtained the resolution by the same definition for $\mathrm{AuL} \alpha$ The results are compared with the ones by various authors in Table 1. As suggested by Joy et al [9], the effect of secondary electrons on spreading is not appreciable for a high value of excitation energy. There is much variety in the results depending on models. It seems that in order to evaluate the accuracy of various theoretical results from a comparison with experiments, it is necessary to take account of the spatial distribution of the generated X-ray intensity, A more detailed study is in progress.

\section{References}

1. J. I. Goldstein, J. L. Costly, G. W. Lorimer and S. J. B. Reed, Scanning Electron Microscopy / 1977 I, p. 315.

2. G. Cliff and G. W. Lorimer, Quantitative Microanalysis with High Spatial Resolution, Book 277 (Metals Society, London, 1981), p. 47.

3. P. Doig, D. Lonsdale and P. E. J. Flewitt, ibid, p. 41.

4. R. Hutchings, M. H. Loretto, I. P. Jones and R. E. Smallman, Ultramicroscopy 3, 401 (1979).

5. D. F. Kyser, Introduction to Analytical Electron Microscopy (Plenum Press, New York, 1979), p. 199.

6. D. E. Newbury and R. L. Myklebust, Ultramicroscopy 3, 391 (1979); Analytical Electron Microscopy, ed. H. Geiss (San Francisco Press, Inc., San Francisco, 1981), p. 91.

7. R. G. Faulkner, T. C. Hopkins and K. Norrgard, X-ray Spectrom. 6, 73 (1977).

8. H. Geiss and D. F. Kyser, Ultramicroscopy 3, 397 (1979).

9. D. C. Joy, D. E. Newbury and R. L. Myklebust, J. Microscopy 128, p. RP1 (1982).

10. K. Murata, D. F. Kyser, and C. H. Ting, J. Appl. Phys., 52, 4396 (1981).

11. K. Murata, S. Cvikevich and J. Kuptsis, Microbeam Analysis - 1983.

12. I. P. Jones, Phil. Mag. A44, 1401 (1981).

13. E. Eggarter, J. Chem. Physics, 62, 833 (1975).

14. D. E. Newbury, Microbeam Analysis - 1982, ed. K. F. J. Heinrich (San Francisco Press, Inc., San Francisco; 1982), p. 79. 


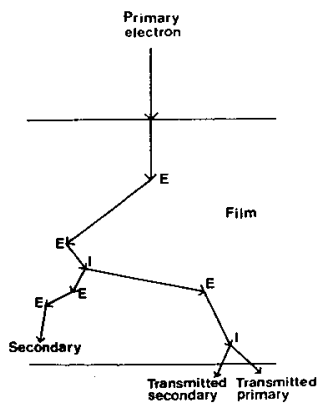

Fig.l Simulation model

(E:elastic, I:inelastic).

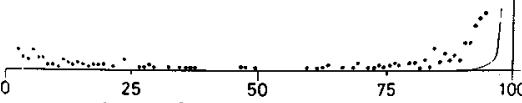
transmitted electron energy (keV)

Fig.2 Energy distribution of transmitted electrons.

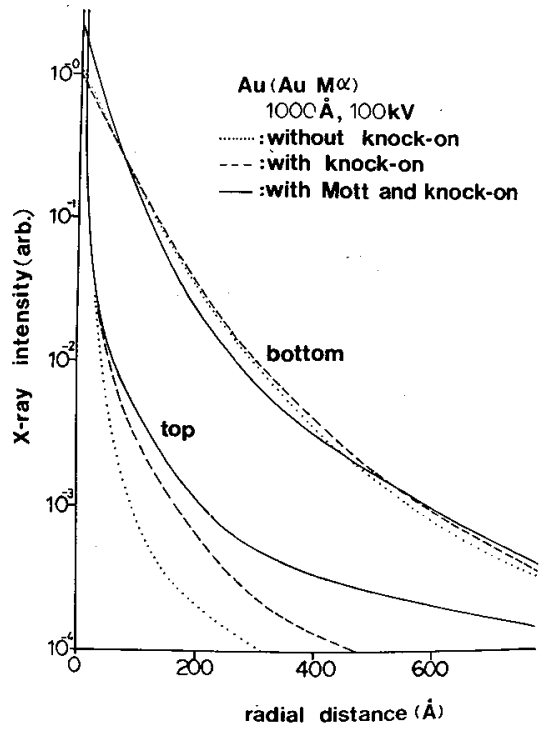

Fig. 3 X-ray intensity distribution

\begin{tabular}{lcc} 
Method & Diameter Ref. \\
\hline Single & $489(\mathbf{A})$ & 1 \\
Plural & 366 & 2 \\
Multiple & 380 & 3 \\
Monte Carlo & 380 & 5 \\
Monte Carlo & 522 & 6 \\
\hline Noknock-on & 460 & Present \\
Knock-on & 465 & model \\
Mott \& knock-on 600 & \\
Table I Spatial Resolution for \\
Au L $\alpha$ (t=1000A, E =lookeV). 14)
\end{tabular}
$1000 \dot{A}, 100 \mathrm{kV}$

---; with knock-on

- with Mott and knock-on $\left\{\begin{array}{r}20100 \\ 10100 \\ \text { dn } \\ \text { dE } \\ 50 \\ 0\end{array}\right.$

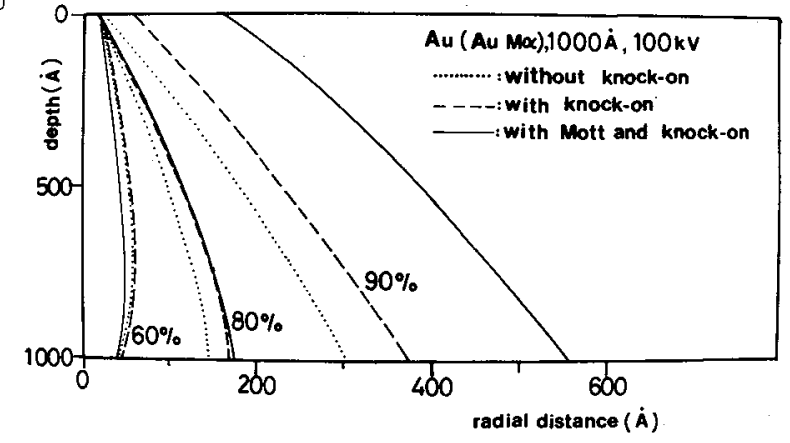

Fig. 5 Generated X-ray intensity iso-contours

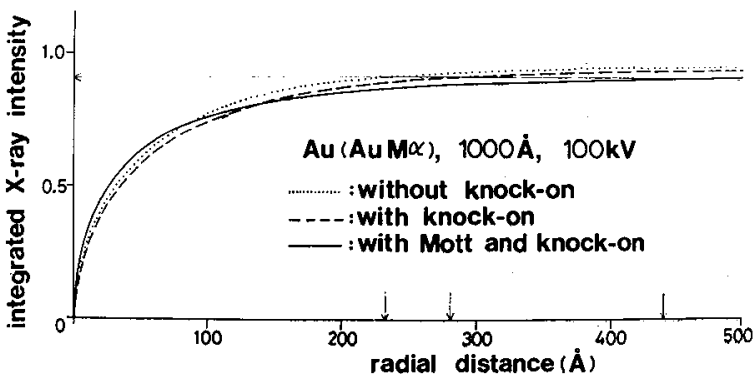

Fig. 6 Integrated $\mathrm{X}-\mathrm{ray}$ intensity (arrows show the radii where normalized intensity is 0.9 for three different cases). 